\title{
Current therapeutic strategies for premature ejaculation and future perspectives
}

\author{
Zhong-Cheng Xin ${ }^{1}$, Yi-Chen Zhu ${ }^{2}$, Yi-Ming Yuan ${ }^{1}$, Wan-Shou Cui ${ }^{1}$, Zhe Jin ${ }^{1}$, Wei-Ren Li $^{1}$ and Tao Liu ${ }^{1}$ \\ Premature ejaculation (PE) is a common sexual disorder in men that is mediated by disturbances in the peripheral and central nervous \\ systems. Although all pharmaceutical treatments for PE are currently used 'off-label', some novel oral agents and some newer methods \\ of drug administration now provide important relief to PE patients. However, the aetiology of this condition has still not been unified, \\ primarily because of the lack of a standard animal model for basic research and the absence of a widely accepted definition and \\ assessment tool for evidence-based clinical studies in patients with PE. In this review, we focus on the current therapeutic strategies \\ and future treatment perspectives for PE.
}

Asian Journal of Andrology (2011) 13,550-557; doi:10.1038/aja.2010.130; published online 2 May 2011

Keywords: 5-HT; dapoxetine; premature ejaculation; sexual disorder; selective serotonin reuptake inhibitor; treatment

\section{INTRODUCTION}

Normal male sexual activity includes sexual libido, penile erection, ejaculation and orgasm, with ejaculation and orgasm composing the final stage of the sexual response cycle.

Ejaculation is a tightly coordinated activity with different ejaculatory organs and a spinal reflex initiated by genital and/or brain stimulation through the peripheral sensory receptors and regions, afferent pathways, the central nervous system ejaculatory centre of the brain (namely, sensory and motor areas located in the para-ventricular nucleus of the hypothalamus and the medial preoptic area). The spinal ejaculatory centre, located at the $\mathrm{T}_{12}-\mathrm{L}_{1-2}$ spinal cord level (paragigantocellular), and its efferent pathway modulate the function of the ejaculatory organs. Ejaculation is also mediated by a complex interaction of central serotonergic and dopaminergic neurons with the secondary involvement of cholinergic, adrenergic, oxytocinergic and GABAergic neurons.

Ejaculation consists of two main phases, the emission phase and the expulsion phase. The emissions include seminal fluid and secretions of the prostate and bulbourethral glands. In this phase, the contraction of accessory ejaculatory organs induces the accumulation of semen in the posterior urethra. Expansion of the posterior urethra creates a feeling of emission and sensory information that is transmitted to the spine via dorsal nerve sensory pathway and along the spinal cord up to the brain ejaculatory centre during the sexual arousal phase. The expulsion phase consists of the highly regular rhythmic contraction of striated muscles and the relaxation of smooth muscles in the ejaculatory ducts. The ejaculated semen can be divided into a number of components by serial biochemical analysis. ${ }^{1}$ These include secretions from the seminal vesicles, prostate and bulbourethral (Cowper's) glands and spermatozoa.
Ejaculatory dysfunction may arise due to a problem in any of these steps and encompasses premature ejaculation (PE), retarded ejaculation, anejaculation, retrograde ejaculation and painful ejaculation. However, PE is the most common type of ejaculatory dysfunction.

During the past four to five decades, the lack of a globally accepted definition has led to difficulties in determining the prevalence of $\mathrm{PE}$, which has been cited as ranging from $4 \%$ to $66 \%{ }^{2,3}$ Defining PE remains controversial. The most recent definition of $\mathrm{PE}$ adopted by the International Society for Sexual Medicine is 'a male sexual dysfunction characterized by ejaculation which always or nearly always occurs prior to or within about one minute of vaginal penetration; and inability to delay ejaculation on all or nearly all vaginal penetrations; and negative personal consequences, such as distress, bother, frustration and/or the avoidance of sexual intimacy'. ${ }^{4} \mathrm{PE}$ is also classified as either primary (lifelong) or secondary (acquired). Primary PE has a disease onset at the time of the initial sexual experience and persists throughout an individual's entire life. Ejaculation occurs too quickly, either before vaginal penetration or less than 1 min afterwards. Secondary PE has either a gradual or a sudden onset and occurs in an individual with a previous history of normal ejaculation. Ejaculatory latency is short but not usually as brief as in primary PE. ${ }^{5}$

Historically, PE was considered a psychological rather than a physiological problem and was treated by behavioural therapy and psychotherapy. Semans ${ }^{6}$ first reported the 'start-stop' technique in 1956, which was modified with psychotherapy by Masters and Johnson $^{7}$ in 1970. Although such therapies may be initially useful for some couples, they are rarely successful in long-term followup. ${ }^{8,9}$ At present, attempts to explain the cause of PE rely on various biological and psychological theories; however, most of these theories

\footnotetext{
${ }^{1}$ Andrology Centre of Peking University First Hospital, Peking University, Beijing 100034, China and ${ }^{2}$ Department of Urology, Beijing Friendship Hospital, Capital Medical University, Beijing 100050, China

Correspondence: Professor ZC Xin (xinzc@bjmu.edu.cn, xinzc08@gmail.com)

Received: 16 September 2010; Revised: 17 January 2011; Accepted: 25 January 2011; Published online: 2 May 2011
} 
are not evidence-based by now. Psychological theories highlight the impact of early sexual experience and sexual conditioning, anxiety, sexual technique, the frequency of sexual activity and other psychodynamic explanations. Factors cited in biological explanations include evolutionary theories, the sensitivity of the penis, central neurotransmitter levels and receptor sensitivity, a certain degree of arousability, the speed of the ejaculation reflex and the sex hormone levels. Common flaws in most of these studies that generated these hypotheses include methodological problems and a lack of interoperability in the definition of PE.

Studies on the aetiology of PE must necessarily rely on research in animal models, which are crucial to investigating the anatomy, physiology, cell biology, biochemistry, pathophysiology and pharmacology of PE, all prerequisites for developing new therapies for the treatment of PE. However, experimental animal models of PE have not yet been developed well to investigate the aetiology, pathophysiology and relevant pharmacology of PE. These fields of study will hopefully stimulate researchers to seek new methods to develop an experimental model of PE in the near future.

Recently, increasing evidence from psychopharmacological studies has suggested that PE may be related, at least in part, to diminished serotonergic neurotransmission. Aided by this recognition of the existence of a neurobiological component underlying the aetiology of PE, the management, especially the pharmacological treatment, of PE has advanced over the past decade. Nevertheless, to date, no oral or topical agent has been approved by the US Food and Drug Administration for the management of PE; however, drug therapy is still often the preferred first-line therapy.

\section{NON-PHARMACOLOGICAL TREATMENT}

As mentioned above, PE is often considered a psychological rather than a physiological problem, and, as such, behavioural psychosexual therapy remains a popular treatment choice. The earliest method of behavioural therapy was described by the urologist Semans $^{6}$ in 1956. In 1970, sex therapists Masters and Johnson ${ }^{7}$ reported a similar manoeuvre that differs slightly from that of Semans. Their technique involves requesting the partner to squeeze the penile fraenulum immediately after cessation of penile stimulation, which can partially restrain erection, and then the female partner restarts the stimulation at least $30 \mathrm{~s} \mathrm{later.}^{8}$ In fact, the primary goals of traditional psychosexual treatment for PE are to increase the male's self-confidence in sexual activity, reduce anxiety, resolve any interpersonal difficulties and improve couple communication. Ejaculation is actually a spinal reflex under strong control from higher central nervous centres, the same as urination and defecation, so control can be learned and is significantly influenced by past experiences. Although behavioural therapy has been shown to have a $45 \%-65 \%$ success rate, the benefits are generally shortlived, and the problem typically reoccurs. ${ }^{9,10}$ However, some researchers have demonstrated that the patients with PE occupy the far left edge of a normal distribution curve of ejaculatory latencies, suggesting serotonin receptor sensitivity as a genetic explanation for psychosexual therapy failure. ${ }^{11}$

Currently, pharmacotherapy and psychotherapy are often proposed in combination for treatment of severe PE. The severe PE patient requires more therapeutic methods than drugs alone. ${ }^{12}$ Two reports have described combination therapy with psychological and medical components administered independently. When clinicians and sex therapists work together as one team to manage severe PE patients, better results could be obtained. ${ }^{12,13}$

\section{PHARMACOLOGICAL TREATMENTS}

Pharmacological modulation of the ejaculatory threshold provides a novel and refreshing approach to the treatment of PE and is completely different from the psychosexual and behavioural treatment model. Because penile hypersensitivity and hyperexcitability have been suggested to contribute to the aetiology of PE, topical desensitizing agents and oral selective serotonin reuptake inhibitors (SSRIs) have been introduced as new therapeutic options. These agents have revolutionized the treatment of PE and are becoming increasingly popular. However, SSRIs were all initially developed to treat other diseases, such as depression and pain; thus, their use in treating PE is considered 'off-label', as they have not yet been approved by the US Food and Drug Administration for this indication. A systematic review and meta-analysis revealed 79 publications on drug treatment for PE involving 3034 men between $1943^{14}$ and $2003 .{ }^{15}$ A recent meta-analysis showed that, in spite of a trend towards more evidence-based research on drug treatments, the majority of studies for PE still lack adequate design and methodology. ${ }^{16}$

Current and widely accepted pharmacological treatment options for PE include antidepressive agents, topical desensitizing agents, phosphodiesterase type 5 inhibitors (PDE-5Is) and $\alpha$-receptor blockers.

\section{Antidepressive agents}

Several studies in male rats have shown that 5-hydroxytryptamine (5HT) and other serotonin receptors are involved in the ejaculation process. ${ }^{17,18}$ Activation of $5-\mathrm{HT}_{2 \mathrm{C}}$ receptors can delay ejaculation, whereas the activation of $5-\mathrm{HT}_{1 \mathrm{~A}}$ receptors speeds up ejaculation. $\mathrm{PE}$ has been attributed, in part, to decreased central serotonergic neurotransmission, $5-\mathrm{HT}_{2 \mathrm{C}}$ receptor hyposensitivity and/or $5-\mathrm{HT}_{1 \mathrm{~A}}$ receptor hypersensitivity. ${ }^{19}$ Thus, $5-\mathrm{HT}_{2 \mathrm{C}}$ receptor agonists, such as SSRIs and serotonergic tricyclic antidepressants, should theoretically help delay ejaculation.

Clomipramine. Clomipramine is a tricyclic antidepressant that inhibits the uptake of noradrenaline and 5-HT by adrenergic and 5-HT neurons, respectively. ${ }^{20}$ In 1973, Eaton ${ }^{21}$ published his novel report on the efficacy of clomipramine, and numerous subsequent publications have confirmed its effectiveness in treating PE. A meta-analysis has shown that daily use of clomipramine increases intravaginal ejaculatory latency time (IELT) by 4.6-fold, which is not statistically different from the effect of sertraline or fluoxetine. ${ }^{15}$ In three double-blind, placebo-controlled crossover studies, ${ }^{22-24}$ on-demand use of clomipramine (25 mg; 12-24 h before intercourse) significantly increased the IELT by approximately fourfold in PE patients. However, only the smallest of these three trials used an objective stopwatch technique for measuring the IELT. In addition, after daily treatment with clomipramine, men with PE reported improved relationship and emotional satisfaction, and their partners reported an increased ability to achieve coital orgasm. ${ }^{25}$

The most common adverse side effect of clomipramine is nausea on the day of sexual intercourse and the following day. With chronic use, adverse events of clomipramine were reported to be significantly more severe than with SSRIs. ${ }^{26}$

SSRIs. The ability of SSRIs to delay ejaculation was first discovered serendipitously as a result of the use of these drugs in the treatment of depression in men in the $1970 \mathrm{~s}^{27}$ At present, four different SSRIs are commonly used in the treatment of PE: fluoxetine, sertraline, paroxetine and citalopram. SSRIs increase synaptic 5-HT concentrations via 
blockade of the 5-HT transporter and activation of the $5-\mathrm{HT}_{2 \mathrm{C}}$ receptor, as previously mentioned, can delay ejaculation. ${ }^{19}$ The extent of such delay depends on the type, dosage and frequency of SSRI administration. Other SSRIs, specifically fluvoxamine ${ }^{28}$ and venlafaxine, ${ }^{29}$ have not proven useful for delaying ejaculation. Although none of these agents has been approved for treating $\mathrm{PE}$, the current American Urological Association guidelines ${ }^{30}$ and the recommendations of the International Consultation on Sexual Dysfunction ${ }^{31}$ suggest the off-label use of SSRIs for managing PE.

A prolongation of delay IELT can be induced by SSRIs as soon as 23 days after the first oral treatment in patients with PE, and this delay tends to plateau after 3-4 weeks at a six- to eightfold increase in the IELT. $^{32,33}$ Although the effects of such drugs are well established, some fundamental questions remain regarding dosing regimen (daily versus on-demand) and efficacy (which SSRI is superior).

In one study where it was used daily, paroxetine was shown to be the most effective SSRI ( 8.8 -fold increase in the IELT), followed by sertraline (4.1-fold) and fluoxetine (3.9-fold). Each of these increases was significantly higher than that induced by placebo (1.4-fold) ${ }^{34}$ A metaanalysis of the use of SSRIs for PE included data from eight randomized, double-blind studies of SSRIs and tricyclic antidepressants for the treatment of PE, including the IELT assessment with stopwatch. The rank order of efficacy, as defined by the increase in IELT, was as follows: paroxetine, sertraline, clomipramine, fluoxetine and placebo. ${ }^{15}$ However, the author has highlighted the unreliability of IELT and the absence of patient-reported outcomes as clear weaknesses of this meta-analysis.

Only a small number of studies have evaluated on-demand use of SSRIs, and according to the existing data, it is difficult to compare the efficacy of on-demand use and daily use of SSRIs. In 2004, Waldinger et $a .^{23}$ investigated the ejaculation delay induced by fixed-dose ondemand treatment with paroxetine and clomipramine in a randomized, double-blind study of 30 PE patients. On-demand treatment of paroxetine $(20 \mathrm{mg}$ ) did not cause clinically relevant delay in ejaculation, but daily use of the same SSRIs for 6 weeks significantly increased the IELT by $146 \mathrm{~s}$. More well-designed, head-to-head trials are required for the assessment of SSRIs used on-demand.

SSRIs may cause side effects such as fatigue, mild nausea, diarrhoea or heavy perspiration. SSRIs have different short-term and long-term adverse effects. The most common short-term adverse effects are yawning, mild nausea, excessive sweating, fatigue and loose stool. Priapism ${ }^{35}$ and loss of bone mineral density ${ }^{36}$ are the most common with longterm treatment. Bleeding ${ }^{37}$ has only rarely been reported in patients with PE, but in patients with depression, it is well known; thus, this adverse effect also requires attention. A reduction in sexual desire and a moderate reduction in penile rigidity have been reported. ${ }^{38}$ These adverse effects are usually mild and gradually disappear within 2-3 weeks of use in most patients. Similar to clomipramine, however, patients should be informed of all these possible side effects before beginning treatment. A sudden reduction or cessation of long-term treatment with an SSRI can lead to 'SSRI discontinuation syndrome', a group of physical and psychological symptoms including nausea, vomiting, dizziness, headache, ataxia, drowsiness, excitement, anxiety and insomnia. These symptoms begin 1-3 days after drug cessation and typically continue for more than 1 week. Side effects are usually reversible with SSRI reintroduction. ${ }^{39}$ Because of the SSRI discontinuation syndrome, it is still recommended that SSRIs are gradually withdrawn over 3-4 weeks, with the exception of fluoxetine. ${ }^{40}$

SSRI overdose or, more commonly, interaction between SSRIs and other agents, can enhance 5-HT activity in the central nervous system to the point of causing the 'serotonin syndrome', a group of serious, persistent symptoms including myoclonus, hyperreflexia, sweating, shivering, discoordination and mental status changes. ${ }^{39}$ Patients receiving long-term SSRI treatment for PE must be aware of potential drug interactions between SSRIs and other concurrent drugs in order to reschedule the doses and timings of different drugs. ${ }^{39}$

Acute SSRI administration. The 5-HT transporter blockade induced by acute administration of all current SSRIs leads to higher 5-HT levels in the synapse and in the space around the cells. ${ }^{41}$ Increasing 5-HT levels activates $5-\mathrm{HT}_{1 \mathrm{~A}}$ autoreceptors, resulting in less 5-HT being released into the synaptic cleft within minutes. ${ }^{42}$ A higher 5-HT concentration increases activation of presynaptic $5-\mathrm{HT}_{1 \mathrm{~B}}$ autoreceptors, which alone can reduce the release of 5-HT. Under normal physiological conditions, the net effect of acute administration of SSRIs is little to no increase in 5-HT neurotransmission and minimal or no stimulation of postsynaptic 5-HT receptors. ${ }^{43}$ Given this background, on-demand SSRI treatment would not be expected to result in acute stimulation of 5-HT postsynaptic receptors. Consequently, one would expect minimal increase in synaptic 5-HT levels and, thus, little or no synaptic stimulation of 5-HT receptors. Little or no activation of postsynaptic 5-HT receptors should then result in no clinically relevant ejaculation delay. ${ }^{43}$

Chronic SSRI administration. In contrast to their acute administration, chronic use of currently available SSRIs causes some physiological changes that delay ejaculation. Ongoing blockade of 5-HT receptors that mediate serotonin reuptake results in a persistent increase in 5-HT levels in the synapse and in the space around the cells. As opposed to the acute administration of SSRIs, this ongoing blockage leads to desensitisation of the 5 - $\mathrm{HT}_{1 \mathrm{~A}}$ autoreceptors in a few weeks, ${ }^{44}$ in addition to possible desensitisation of $5-\mathrm{HT}_{1 \mathrm{~B}}$ autoreceptors $^{45}$ and therefore less inhibition of 5-HT release into the synapse. The net effect of the chronic administration of SSRIs is an increase in the 5-HT released into the synapse and enhanced 5-HT neurotransmission, thus resulting in a stronger activation of the 5 -HT receptors compared with that observed in acute SSRI administration. ${ }^{46}$ These data predict that daily treatment of SSRI will stimulate the 5-HT postsynaptic receptors, leading to a clinically relevant ejaculation delay after $1-2$ weeks of continuous intake. ${ }^{43}$

\section{Tramadol}

Tramadol is a synthetic opioid analgesic active in the central nervous system with a $C_{\max }$ of $300 \mu \mathrm{g} \mathrm{l}^{-1}$ after a single oral dose of $100 \mathrm{mg} .{ }^{47}$ Tramadol is registered as a central analgesic, has been used for many years and has a widely accepted safety profile, despite the fact that its mechanism of action is not fully understood. Based on animal experiments, at least two different mechanisms are likely: one enantiomer exerts a major weak $\mu$-opioid effect, while the other inhibits norepinephrine and serotonin reuptake, activating descending monoaminergic inhibitory pathways. ${ }^{48,49}$ Tramadol's inhibition of the reuptake of norepinephrine and serotonin may explain its ability to delay ejaculation. ${ }^{49}$ However, its induction of $5-\mathrm{HT}_{1 \mathrm{~A}}$ and $5-\mathrm{HT}_{2 \mathrm{C}}$ also requires further investigation.

Two recently published studies assessed the effectiveness of ondemand use of tramadol for the treatment of PE. ${ }^{49,50}$ Safarinejad and Hosseini ${ }^{50}$ reported on-demand use of tramadol (50 mg) to have a significant impact on IELT delay in PE patients. In a double-blind, placebo-controlled study, on-demand use of tramadol $50 \mathrm{mg}$, taken $2 \mathrm{~h}$ before sexual intercourse, was associated with a clinically significant 
ejaculation delay in the treatment of PE. Of those taking tramadol, $28 \%$ reported adverse effects. The most common side effects were nausea (15.6\%), vomiting (6.2\%) and dizziness (6.2\%) but these were all mild. In another study by Salem et al. evaluating on-demand treatment with $25 \mathrm{mg}$ Tramadol, ${ }^{49}$ the treatment group experienced a 6.3fold increase in IELT compared with a 1.7-fold increase in the placebo group. In this study, $13.3 \%$ of patients reported adverse effects, including dyspepsia and mild sleepiness. ${ }^{49}$ Although tramadol is an interesting on-demand PE drug and preliminary results are encouraging, further studies are needed. Tramadol also has a weak n-opioid agonistic effect; consequently, long-term follow-up study is necessary to assess the risk of opioid addiction with this drug.

\section{PDE-5Is}

At least $30 \%$ of men with $\mathrm{PE}$ also suffer from erectile dysfunction (ED) ${ }^{51}$ Patients suffering from ED may ejaculate soon after erection and before the failure-to-maintain phase of the erection sets in. ${ }^{52}$ Some experiments have shown a relationship between ejaculation function and PDE-5. Mancina et al. ${ }^{53}$ demonstrated the expression of PDE-5 in all human and rabbit vas deferens muscles. Kriegsfeld et $a l^{54}$ showed that ejaculation can be inhibited by nitric oxide in nongenetically altered mice, and this effect most likely is modulated by reduced sympathetic nervous system activity. PDE-5Is have also been successfully used in the management of the subgroup of ED patients with comorbid PE.

PDE-5I has been used alone ${ }^{55,56}$ or in combination with SSRIs ${ }^{57}$ for the treatment of PE. Although the only double-blind, placebo-controlled, parallel group study of sildenafil citrate for the treatment of PE showed no significant improvement in IELT and vibrotactile stimulation compared with placebo, the sildenafil group had a statistically significant increase in ejaculation control $(1.8 \pm 0.3$ versus $1.5 \pm 0.3$, $P<0.05){ }^{55}$ In another study, on-demand sildenafil use increased ejaculation time as induced by vibratory stimulation compared with that in the placebo group. ${ }^{56}$ Two studies of vardenafil for PE showed that it increases IELT and reduces the post-ejaculation refractory period in men with lifelong PE. ${ }^{58,59}$

A double-blind, prospective, crossover study compared the effectiveness of sildenafil with the squeeze technique and on-demand use of two different SSRIs (paroxetine and sertraline) and clomipramine in patients with primary PE. Sildenafil demonstrated a 15 -fold increase in IELT compared with two- to fourfold increases for the other groups. ${ }^{60}$ Another study examined the combination of paroxetine and sildenafil and demonstrated that combination therapy increased IELT and sexual satisfaction but that this therapy resulted in a higher incidence of side effects. ${ }^{57}$ In general, studies have shown that PDE-5Is alone or in combination with SSRIs may increase the IELT of patients with ED and concurrent PE.

However, other studies have indicated that sildenafil does not affect the sexual function of men without comorbid ED, but rather leads to a reduction in the post-ejaculation refractory period. ${ }^{61,62}$ A recent systematic review of published reports of PDE-5I for PE found limited evidence to support the use of PDE-5I in treating PE, although some data suggest that these medications may benefit men with both PE and ED. ${ }^{62}$ In short, these studies failed to demonstrate any significant benefit in patients with $\mathrm{PE}$ in the absence of comorbid ED.

\section{$\alpha 1$-adrenoceptor antagonist}

Ejaculation is controlled by the sympathetic nervous system. Therefore, $\alpha$-blockers have also been hypothesized to be effective in the treatment of PE. Some animal studies have demonstrated stimulation of the hypogastric nerve to reduce the pressure on the seminal vesicle. ${ }^{63}$ In one study, treatment with an $\alpha 1$-adrenergic receptor antagonist resulted in significant improvement in 50\% of primary psychogenic PE patients resistant to psychotherapy. ${ }^{64}$ Another very small study with short-term follow-up also suggested that treatment with an $\alpha 1$-receptor blocker may be beneficial for patients with $\mathrm{PE}$ and concurrent lower urinary tract symptom. ${ }^{65}$

\section{Topical agent}

Xin et al. ${ }^{6,67}$ proposed that the aetiology of PE is hypersensitivity of the penis, and, thus, one of the goals of PE treatment is to reduce the sensory perception of the penis and the penis biothesiometry studies have shown patients with PE to have higher penile sensitivity, which is not age-dependent. Schapiro ${ }^{14}$ described using local anaesthetic agents for PE in 1943, the first documented topical therapy for PE. The topical agents were originally used 'off-label' in the treatment of PE. Compared with systemic therapy, local treatment is appealing because these agents could be used ondemand and minimal systemic side effects. However, the application of topical agents does result in a number of adverse events, including penis hypoaesthesia, ED, female genital anaesthesia and skin reactions. Topical agents currently available for PE treatment include severance secret cream (SS-cream), lidocaine cream, prilocaine cream and lidocaine spray.

SS-cream. SS-cream (CJ Co. Ltd, Seoul, Korea), developed at YongDong Severance Hospital in Korea, is made from the extracts of nine natural products. It is applied to the penis $1 \mathrm{~h}$ before sexual intercourse and washed off prior to intercourse. SS-cream is available only in Korea and is not approved for use in other countries. Studies have reported both the latency and the amplitude of somatosensory-evoked potentials measured at the glans penis to be increased relative to baseline after local application of SS-cream, ${ }^{68}$ which also have shown penile vibration threshold increase. ${ }^{69}$ Xin et al. ${ }^{70}$ reported the ejaculation latency to be significantly prolonged-more than $2 \mathrm{~min}$-in $89.2 \%$ of patients using SS-cream. In a multicentre, double-blind study involving 106 cases, the use of $0.2 \mathrm{~g}$ SS-cream was reported to increase the mean IELT measured by stopwatch from a baseline of 1.37-10.92 $\mathrm{min}$, compared with $2.45 \mathrm{~min}$ with placebo $(P<0.001)$; this treatment was also 27 times more effective than placebo in enhancing sexual satisfaction $(P<0.001) .^{71}$ The main disadvantage of SS-cream is the unpleasant odour and colour, which makes it unacceptable to many patients. A novel formulation, named 'Renewal SS-cream', is a new local agent composed of the two principal components of the original SS-cream. In rabbits, the renewed SS-cream delays the latency of spinal somatosensory-evoked potential more effectively than does the original SS-cream. ${ }^{72}$

Lidocaine-prilocaine cream. Lidocaine and prilocaine form a liquid eutectic mixture when mixed with equal parts by weight, resulting in a higher concentration of anaesthetic at the time of application. The eutectic mixture of local anaesthetics (AstraZeneca, London, UK) is a cream containing $2.5 \%$ lidocaine/prilocaine for topical usage with the ability to anaesthetize intact skin. It is available in some countries.

However, published studies of lidocaine and prilocaine cream are scarce. The largest double-blind clinical trial of lidocaine-prilocaine cream enrolled 42 cases in two groups. Treatment resulted in a 5.6-fold increase in IELT. However, only 29 of the initial 42 participants completed the study. A total $16 \%$ of patients with adverse effects reported penile numbness, retarded ejaculation, penile irritation and decreased 
vaginal sensitivity. ${ }^{73}$ Another placebo-controlled study reported the optimal application time to be 20 min prior to intercourse. ${ }^{74}$

Lidocaine spray. Another topical agent, lidocaine, has been available for more than 25 years in some countries. Both 9.6\% lidocaine and $9.6 \%$ lidocaine mixed spray are available. Although manufacturers claim that the spray had the ability to delay ejaculation, reliable data from clinical trials are absent; therefore, its efficacy and safety cannot be assessed. ${ }^{75}$

\section{FUTURE PERSPECTIVES ON THE TREATMENT FOR PE}

Curing PE remains a distant goal. The ideal treatment for PE would be a novel medication that is rapid-acting and effective on an on-demand basis, without sexual side effects (e.g., diminished libido and ED) and without generalized side effects (e.g., nausea, insomnia and headache).

\section{On-demand therapy of SSRIs}

Although chronic administration of SSRIs has been successful in the treatment of PE, side effects, such as dry mouth, headache and dizziness, have presented a problem. ${ }^{24}$ Therefore, it is understandable that patients are reluctant to accept the continued and long-term administration of SSRIs. ${ }^{17,76}$ To minimize these side effects and better target the patient's needs in a cost-effective manner, the on-demand use of SSRI has been proposed. ${ }^{24}$ Some studies have evaluated the use of SSRI antidepressants and 'as needed' dosing, but the study designs were not rigorous. ${ }^{28,77}$ In recent years, however, several pharmaceutical companies have become interested in on-demand treatment of PE with SSRIs that have a short half-life and a very short period to attain maximum concentration. An example of such a drug is dapoxetine.

Dapoxetine. Dapoxetine is a new agent designed for the purpose of treating PE. Dapoxetine ((+)-(S)-N,N-dimethyl-(a)-[2-(1-naphthalenyloxy)ethyl]-benzenemethanamine) hydrochloride is a water-soluble, white to off-white powder with a molecular weight of $341.88 \mathrm{Da}$. Dapoxetine has a pKa value of 8.6 and is mainly charged at physiological $\mathrm{pH}$. These features allow for its rapid distribution in the body. Pharmacological research shows dapoxetine to be a potent inhibitor of serotonin transporters. ${ }^{78}$ Although its pharmacological activity is similar to that of clomipramine and that of conventional SSRIs, chemical features of the structure of dapoxetine and its pharmacokinetic profile differentiate it from other SSRIs. ${ }^{79}$

Dapoxetine has a unique pharmacokinetic profile that allows a relatively rapid achievement of high serum concentrations (time to maximum serum concentration: $1.29 \mathrm{~h})^{79}$ and rapid elimination (half-life: $1.49 \mathrm{~h}$ ) after oral dosing, which might contribute to its utility as an on-demand therapy for PE. ${ }^{79}$ In two 12 -week placebo-controlled trials in the United States enrolling 2614 moderate or severe PE patients, on-demand administration of 30 or $60 \mathrm{mg}$ dapoxetine significantly improved outcomes compared with a placebo. The IELT was significantly $(P<0.001)$ increased, up to 3.6 -fold over baseline versus 1.9-fold for placebo. Patient-reported perception of control over ejaculation and satisfaction with sexual intercourse was also significantly better than both baseline values and placebo. ${ }^{80}$ The most common adverse events with 30 and $60 \mathrm{mg}$ dapoxetine in these 12 week trials in the United States were nausea $(8.7 \%$ and $20.1 \%$, respectively versus $1.9 \%$ with placebo), diarrhoea (3.9\% and $6.8 \%$, respectively versus $1.4 \%$ with placebo), headache $(5.9 \%$ and $6.8 \%$, respectively versus $4.0 \%$ with placebo) and dizziness $(3.0 \%$ and $6.2 \%$, respectively versus $0.8 \%$ with placebo), and $5 \%$ of all subjects discontinued because of adverse events. ${ }^{80}$
Another well-designed, randomized, double-blind, multicentre, placebo-controlled, phase 3 , randomized clinical trial was published in $2009 .^{81}$ It involved 618 men with PE separated into dapoxetine $30 \mathrm{mg}$, dapoxetine $60 \mathrm{mg}$ and placebo groups. In this trial, IELT and the other outcomes assessed improved significantly more with dapoxetine than with placebo $(P<0.001$ for all). The adverse effects were similar to those previously reported. Results from a 9-month, openlabel extension study that assessed dapoxetine $60 \mathrm{mg}$ revealed the most common adverse events to be nausea (15.4\%), dizziness $(5.1 \%)$ and headache $(4.6 \%)$, and $6.7 \%$ of subjects withdrew due to adverse events, including nausea $(1.6 \%)$, dizziness $(1 \%)$, diarrhoea $(0.8 \%)$, headache $(0.6 \%)$ and insomnia $(0.5 \%){ }^{82}$ In addition, dapoxetine has been already approved for the treatment of $\mathrm{PE}$ in seven European countries: Austria, Finland, Germany, Italy, Portugal, Spain and Sweden. ${ }^{5}$

Other SSRIs with a short half-life. In addition to dapoxetine, which is produced by Alza/Johnson \& Johnson, Pfizer Inc. and Bristol-Myers Squibb have similar patent agents under development. ${ }^{76}$ The BristolMyers Squibb drug, BMS-505130, is a powerful and selective SSRI with a short half-life and a slight advantage in the treatment of PE because its concentration in plasma declines rapidly after dosing. ${ }^{83}$ Although specific data on these candidate drugs are not available by now, the Pfizer drug (UK 390957; Pfizer Inc., New York, USA) has been described as a rapid-acting serotonin modulator as well as a shortacting SSRI. $^{84}$

\section{Novel topical agents}

Prilocaine-Lidocaine spray. The topical eutectic mixture for $\mathrm{PE}$ (Plethora Solutions Holdings PLC, London, UK) is a metered-dose spray of lidocaine and prilocaine under development. Its metereddose aerosol-delivery system is specifically designed for use in treating PE. The system delivers a 7.5-mg lidocaine base plus a 2.5 -mg prilocaine base per actuation. ${ }^{85}$ The first open-label pilot study involved 11 cases in which the IELT was recorded by stopwatch. Using the spray $15 \mathrm{~min}$ before intercourse, the average IELT increased from 1.40 to $11.35 \mathrm{~min}(P=0.008)$. In addition, eight of 11 patients and seven of 11 partners reported their sexual satisfaction after the spray as 'better' or 'much better', respectively. ${ }^{75}$ In a phase II placebo-controlled trial recently published, ${ }^{86} 54$ patients using topical eutectic mixture for PE prolonged their IELT from a mean baseline of 1.0 to $4.9 \mathrm{~min}$. Only three cases (12\%) experienced hypoaesthesia (numbness in the penis) and four experienced ED; none interrupted treatment as a result. Topical eutectic mixture for PE was also well tolerated by the female partners.

Dyclonine/alprostadil cream. Dyclonine is a local anaesthetic most commonly used in dentistry. It is under development as a topical agent (NexMed Inc., San Diego, CA, USA) for treatment of PE as a cream formulation in combination with alprostadil and prostaglandin E1. A pilot study (in summary form) involved 30 patients who applied the cream 5-20 min before intercourse. ${ }^{87}$ There was a significant synergistic effect observed with the cream containing $0.5 \%$ dyclonine/ $0.4 \%$ alprostadil compared with creams containing $1 \%$ dyclonine alone or $0.4 \%$ alprostadil alone $(P<0.05)$. The mean IELTs after dosing were 2.34 and $4.08 \mathrm{~min}$ in the placebo and dyclonine/alprostadil combination groups, respectively $(P<0.05)$. Adverse events were reported by $17.5 \%$ of men. The most frequently reported adverse events were application site-related, such as penile burning, genital pain and genital swelling. The problems were mainly solved in $2 \mathrm{~h}$. 


\section{Therapeutical combination}

5- $\mathrm{HT}_{1 \mathrm{~A}}$ receptor antagonist and an SSRI. For those patients with severe $\mathrm{PE}$, some researchers have suggested that on-demand SSRIs for PE should be able to induce at least a five- to sixfold IELT delay within 1$2 \mathrm{~h}$. While at present such persistent strong-acting, on-demand SSRIs are not available, some data provided from animal studies have indicated that, in principle, such a potent acute ejaculation delay induced by SSRIs should be achievable if treatment is combined with a $5-\mathrm{HT}_{1 \mathrm{~A}}$ receptor antagonist.

Desensitisation of receptors due to chronic SSRI exposure can be imitated in acute treatment by blocking $5-\mathrm{HT}_{1 \mathrm{~A}}$ autoreceptors through co-administration of a $5-\mathrm{HT}_{1 \mathrm{~A}}$ receptor antagonist and an SSRI. In an in vivo microdialysis study, when a selective $5-\mathrm{HT}_{1 \mathrm{~A}}$ receptor antagonist WAY-100635 was combined with citalopram, WAY100635 was able to increase extracellular 5-HT concentrations. ${ }^{88}$ Williamson et al. ${ }^{89}$ tried another $5-\mathrm{HT}_{1 \mathrm{~A}}$ receptor antagonist, robalzotan, in combination with fluoxetine and citalopram in male mice. Neither fluoxetine nor citalopram affected ejaculation latency at day 1. However, at day 11, fluoxetine was shown to significantly increase ejaculation time, whereas citalopram had no such effect. Interestingly, both acute and chronic co-administration of fluoxetine or citalopram and robalzotan significantly delayed ejaculation time. ${ }^{89}$ de Jong et al..$^{90}$ administered citalopram, WAY-100635, and citalopram and WAY-100635 together to male rats. In this study, WAY100635 alone had no effect on ejaculation latency. Chronic treatment with citalopram alone diminished ejaculation frequency. However, both acute and chronic co-administration of citalopram and WAY100635 delayed ejaculation time immediately. The results of these studies may lead to the conclusion that $5-\mathrm{HT}_{1 \mathrm{~A}}$ receptor blockers do not change ejaculatory latency alone, but do so during SSRI treatment. However, human studies are needed to provide more evidence of effectiveness and safety in men.

Behavioural and physiological therapy. To increase the success of PE treatment, a new perspective is to combine behavioural and physiological therapy. PE is a multidimensional condition, and it most likely reflects a physiological response in combination with intraphysical and interpersonal problems. Perelman ${ }^{13}$ suggests that doctors and sex therapists working together might significantly improve initial and long-term treatment response rates for PE by combining the two disciplines. Growing evidence indicates that combination therapy using the new drug and psychological therapy has become a new treatment choice for PE.

\section{Oxytocin}

Immunohistochemical studies have revealed that local synthesis of oxytocin and its synthesis-associated protein, neurophysin I, occurs in the epithelial cells of the epididymis. ${ }^{91}$ Therefore, as an alternative to the SSRI approach, the use of oxytocin as a potential therapeutic agent in the treatment of PE is under investigation. ${ }^{76}$

\section{Surgical treatment}

To decrease penile sensitivity, some have reported the selective resection of branches of the dorsal nerves of penis for treatment of lifelong PE. ${ }^{92}$ Although this treatment seems to be effective, such an invasive therapy still lacks animal studies on safety and efficacy. Furthermore, indication of such a therapy, surgical technique, adverse event and long-term efficacy and safety still require further assessment in large-sample, prospective, randomized controlled trials. Thus surgical treatment could not be recommended as a therapeutic method on PE by now.

\section{Animal model}

Researching the aetiology of PE and developing a treatment agent for $\mathrm{PE}$ are challenging due to the difficulty in setting up a standard animal model of PE. Most of our current animal studies use rats or rabbits with normal sexual behaviour. ${ }^{93}$ In other words, the restriction on the development of animal models of PE is one of the primary factors limiting the development of PE therapy. Olivier et al. ${ }^{94}$ and Pattij et al. ${ }^{95,96}$ reported an animal model of PE that could be used to study delayed ejaculation. In this model, a large number of male Wistar rats were observed over 4-6 weeks using sexual behavioural tests. Fast and slow ejaculatory rats were distinguished based on the number of ejaculations during 30-min tests, each presenting almost $10 \%$ at both ends of the Gaussian distribution. However, a standard guideline with a more convenient way to set up PE animal models still needs to be developed.

\section{SUMMARY}

Research in PE therapy is currently experiencing an upsurge. Although all current pharmaceutical treatments are 'off-label', some novel oral agents and established methods of drug administration now provide important relief for PE patients. Research interest in PE therapy is probably due to the high incidence of PE and the increased needs of men afflicted with this condition. However, the lack of a widely accepted definition and assessment tools is still a major hindrance to $\mathrm{PE}$ research. Furthermore, the aetiology is still not unified. Moreover, in our opinion, the most important priorities that need to be addressed in the research of PE are the lack of a standard animal model and adequately powered aetiological studies enrolling both PE patients and unafflicted control males. There remains a long way to go in terms of future research.

\section{COMPETING FINANCIAL INTERESTS}

The authors declare no competing financial interests.

\section{ACKNOWLEDGMENTS}

This work was supported by the National Natural Science Foundation of China (No. 30772285) and the Beijing Municipal Science and Technology Commission Fund (No. Z08050703320000).

1 Eliasson R. Human Semen and Fertility Regulation in Men. St Louis, , MO: Mosby; 1976. p44.

2 Laumann EO, Paik A, Rosen RC. Sexual dysfunction in the United States: prevalence and predictors. JAMA 1999; 281: 537-44.

3 Carson C, Gunn K. Premature ejaculation: definition and prevalence. Int J Impot Res 2006; 18 (Suppl 1): S5-13.

4 McMahon CG, Althof SE, Waldinger MD, Porst H, Dean J et al. An evidence-based definition of lifelong premature ejaculation: report of the International Society for Sexual Medicine (ISSM) ad hoc committee for the definition of premature ejaculation. J Sex Med 2008; 5: 1590-606.

5 Hatzimouratidis K, Amar E, Eardley I, Giuliano F, Hatzichristou D et al. Guidelines on male sexual dysfunction: erectile dysfunction and premature ejaculation. J Eur Urol 2010; 57: 804-14.

6 Semans JH. Premature ejaculation: a new approach. South Med J 1956; 49: 353-8.

7 Masters WM, Johnson VE. Human Sexual Inadequacy. Boston, , MA: Little, Brown and Company; 1970.

8 Metz M, McCarthy B. Coping with Premature Ejaculation: How to Overcome PE, Please Your Partner and Have Great Sex. Oakland, , CA: New Harbinger; 2003. p79.

9 Lawrence JS, Madakasira S. Evaluation and treatment of premature ejaculation: a critical review. Int J Psychiatry Med 1992; 22: 77-97.

10 Hawton K, Catalan J, Martin P, Fagg J. Long-term outcome of sex therapy. Behav Res Ther 1986; 24: 665-75.

11 Gurkan L, Oommen M, Hellstrom W. Premature ejaculation: current and future treatments. Asian J Androl 2008; 10: 102-9.

12 Althof S. The psychology of premature ejaculation: therapies and consequences. J Sex Med 2006; 3 (Suppl 4): 324-31. 
13 Perelman MA. A new combination treatment for premature ejaculation: a sex therapist's perspective. J Sex Med 2006; 3: 1004-12.

14 Schapiro B. Premature ejaculation: a review of 1130 cases. J Urol 1943; 50: 374-9.

15 Waldinger MD, Zwinderman $\mathrm{AH}$, Schweitzer $\mathrm{DH}$, Olivier B. Relevance of methodological design for the interpretation of efficacy of drug treatment of premature ejaculation: a systematic review and meta-analysis. Int J Impot Res 2004; 16: 369-81.

16 Waldinger MD. Towards evidenced based drug treatment research on early ejaculation: a critical evaluation of methodology. Int J Impot Res 2003; 15: 309-13.

17 Giuliano F. 5-Hydroxytryptamine in premature ejaculation: opportunities for therapeutic intervention. Trends Neurosci 2007; 30: 79-84.

18 Olivier B, van Oorschot R, Waldinger MD. Serotonin, serotonergic receptors, selective serotonin reuptake inhibitors and sexual behaviour. Int Clin Psychopharmacol 1998; 13 (Suppl 6): S9-14.

19 Waldinger M, Olivier B. Utility of selective serotonin reuptake inhibitors in premature ejaculation. Curr Opin Invest Drugs 2004; 5: 743-7.

20 Gur E, Lerer B, Newman ME. Chronic clomipramine and triiodothyronine increase serotonin levels in rat frontal cortex in vivo: relationship to serotonin autoreceptor activity. J Pharmacol Exp Ther 1999; 288: 81-7.

21 Eaton $\mathrm{H}$. Clomipramine in the treatment of premature ejaculation. J Int Med Res 1973; 1: 432-4.

22 Strassberg DS, de Gouveia Brazao CA, Rowland DL, Tan P, Slob AK. Clomipramine in the treatment of rapid (premature) ejaculation. J Sex Marital Ther 1999; 25: 89-101.

23 Waldinger MD, Zwinderman AH, Olivier B. On-demand treatment of premature ejaculation with clomipramine and paroxetine: a randomized, double-blind fixeddose study with stopwatch assessment. Eur Urol 2004; 46: 510-6.

24 Haensel SM, Rowland DL, Kallan KT. Clomipramine and sexual function in men with premature ejaculation and controls. J Urol 1996; 156: 1310-5.

25 Althof SE, Levine SB, Corty EW, Risen CB, Stern EB et al. A double-blind crossover trial of clomipramine for rapid ejaculation in 15 couples. J Clin Psychiatry 1995; 56: 402-7.

26 Kim SC, Seo KK. Efficacy and safety of fluoxetine, sertraline and clomipramine in patients with premature ejaculation: a double-blind, placebo controlled study. J Urol 1998; 159: 425-7.

27 Patterson WM. Fluoxetine induced sexual dysfunction (letter). J Clin Psychiatry 1993; 54: 71.

28 Waldinger MD, van de Plas A, Pattij T, van Oorschot R, Coolen LM et al. The selective serotonin re-uptake inhibitors fluvoxamine and paroxetine differ in sexual inhibitory effects after chronic treatment. Psychopharmacology (Berl)2002; 160: 283-9.

29 Kilic S, Ergin H, Baydinc YC. Venlafaxine extended release for the treatment of patients with premature ejaculation: a pilot, single-blind, placebo-controlled, fixeddose crossover study on short-term administration of an antidepressant drug. Int $J$ Androl 2005; 28: 47-52.

30 Montague DK, Jarow J, Broderick G, Dmochowski RR, Heaton JP et al. AUA guideline on the pharmacologic management of premature ejaculation. J Urol2004; 172: 290 4.

31 Lue TF, Giuliano F, Montorsi F, Rosen RC, Andersson KE et al. Summary of the recommendations on sexual dysfunctions in men. J Sex Med 2004; 1: 6-23.

32 McMahon CG, Abdo C, Incrocci L, Perelman M, Rowland D et al. Disorders of orgasm and ejaculation in men. J Sex Med 2004; 1: 58-65.

33 Seftel AD. Male and Female Sexual Dysfunction. London: Mosby; 2004. pp204-37.

34 Waldinger MD. Premature ejaculation: definition and drug treatment. Drugs 2007; 67: 547-68.

35 Dent LA, Brown WC, Murney JD. Citalopram-induced priapism. Pharmacotherapy 2002; 22: 538-41.

36 Haney EM, Chan BK, Diem SJ, Ensrud KE, Cauley JA et al. Association of low bone mineral density with selective serotonin reuptake inhibitor use by older men. Arch Intern Med 2007; 167: 1246-51.

37 Halperin D, Reber G. Influence of antidepressants on hemostasis. Dialogues Clin Neurosci 2007; 9: 47-59

38 Montejo AL, Llorca G, Izquierdo JA, Rico-Villademoros F. Incidence of sexual dysfunction associated with antidepressant agents: a prospective multicenter study of 1022 outpatients. Spanish Working Group for the Study of Psychotropic-Related Sexual Dysfunction. J Clin Psychiatry 2001; 62 (Suppl 3): 10-21.

39 Giuliano F, Clement P. Serotonin and premature ejaculation: from physiology to patient management. Eur Urol 2006; 50: 454-66

40 Walsh PC. Campbell-Walsh Urology. 9th edn, Vol. 1. Philadelphia, , PA: SaundersElsevier; 2007. pp750-87.

41 Fuller RW. Uptake inhibitors increase extracellular serotonin concentration measured by brain microdialysis. Life Sci 1994; 55: 163-7.

42 de Montigny C, Blier P, Caille G, Kouassi E. Pre- and postsynaptic effects of zimelidine and norzimelidine on the serotoninergic system: single cell studies in the rat. Acta Psychiatr Scand Supp/ 1981; 290: 79-90.

43 Waldinger MD, Schweitzer DH, Olivier B. On-demand SSRI treatment of premature ejaculation: pharmacodynamic limitations for relevant ejaculation delay and consequent solutions. J Sex Med 2005; 2: 121-31.

44 Blier P, Montigny DC. Electrophysiological investigations on the effect of repeated zimelidine administration on serotonergic neurotransmission in the rat. $J$ Neurosci 1983; 3: 1270-8.

45 Chaput $\mathrm{Y}$, Blier P, de Montigny C. In vivo electrophysiological evidence for the regulatory role of autoreceptors on serotoninergic terminals. J Neurosci 1986; 6 : 2796-801.
46 Blier $\mathrm{P}$, Chaput $\mathrm{Y}$, de Montigny $\mathrm{C}$. Long-term 5-HT reuptake blockade, but not monoamine oxidase inhibition, decreases the function of terminal 5-HT autoreceptors: an electrophysiological study in the rat brain. Naunyn Schmiedebergs Arch Pharmacol 1988; 337: 246-54.

47 Lintz W, Becker R, Gerloff J, Terlinden R. Pharmacokinetics of tramadol and bioavailability of enteral tramadol formulations. 4th communication: drops (without ethanol). Arzneimittelforschung 2000; 50: 99-108.

48 Frink MC, Hennies HH, Engelberger W, Haurand M, Wilffert B. Influence of tramadol on neurotransmitter systems of the rat brain. Arzneimittelforschung 1996; 46: 102936

49 Salem EA, Wilson SK, Bissada NK, Delk JR, Hellstrom WJ et al. Treatment of premature ejaculation with tramadol HCL. J Sex Med 2008; 5: 188-93.

50 Safarinejad MR, Hosseini SY. Safety and efficacy of tramadol in the treatment of premature ejaculation. J Clin Psychopharmacol 2006; 26: 27-31.

51 Laumann EO, Nicolosi A, Glasser DB, Paik A, Gingell C et al. Sexual problems among women and men aged 40-80 y: prevalence and correlates identified in the Global Study of Sexual Attitudes and Behaviors. Int J Impot Res 2005; 17: 39-57.

52 Jannini EA, Lombardo F, Lenzi A. Correlation between ejaculatory and erectile dysfunction. Int J Androl 2005; 28 (2 Suppl): 40-5.

53 Mancina R, Filippi S, Marini M, Morelli A, Vignozzi L et al. Expression and functional activity of phosphodiesterase type 5 in human and rabbit vas deferens. Mol Human Reprod 2005; 11: 107-15.

54 Kriegsfeld LJ, Demas GE, Huang PL, Burnett AL, Nelson RJ. Ejaculatory abnormalities in mice lacking the gene for endothelial nitric oxide synthase (eNOS-/-). Physiol Behav 1999; 67: 561-6.

55 McMahon C, Stuckey B, Andersen M, Purvis K, Koppiker N et al. Efficacy of sildenafil citrate (Viagra) in men with premature ejaculation. J Sex Med 2005; 2: 368-75.

56 Ekmekcioglu O, Inci M, Demirci D, Tatlisen A. Effects of sildenafil citrate on ejaculation latency, detumescence time, and refractory period: placebo-controlled, double-blind, crossover laboratory setting study. Urology 2005; 65: 347-52.

57 Salonia A, Maga T, Colombo R, Scattoni V, Briganti A et al. A prospective study comparing paroxetine alone versus paroxetine plus sildenafil in patients with premature ejaculation. J Urol 2002; 168: 2486-9.

58 Aversa A, Pili M, Francomano D, Bruzziches R, Spera E et al. Effects of vardenafil administration on intravaginal ejaculatory latency time in men with lifelong premature ejaculation. Int J Impot Res 2009; 21: 221-7.

59 Mathers MJ, Klotz T, Roth S, Lummen G, Sommer F. Safety and efficacy of vardenafil versus sertraline in the treatment of premature ejaculation: a randomised prospective and crossover study. Andrologia 2009; 41: 169-75.

60 Abdel-Hamid IA, EI Naggar EA, EI Gilany AH. Assessment of as needed use of pharmacotherapy and the pause-squeeze technique in premature ejaculation. Int $J$ Impot Res 2001; 13: 41-5.

61 Mondaini N, Ponchietti R, Muir GH, Montorsi F, di Loro F et al. Sildenafil does not improve sexual function in men without erectile dysfunction but does reduce the postorgasmic refractory time. Int J Impot Res 2003; 15: 225-8.

62 McMahon CG, McMahon CN, Leow LJ, Winestock CG. Efficacy of type-5 phosphodiesterase inhibitors in the drug treatment of premature ejaculation: a systematic review. BJU Int 2006; 98: 259-72.

$63 \mathrm{Kim} \mathrm{SW}$, Lee SH, Paick JS. In vivo rat model to measure hypogastric nerve stimulationinduced seminal vesicle and vasal pressure responses simultaneously. Int J Impot Res 2004; 16: 427-32.

64 Cavallini G. Alpha-1 blockade pharmacotherapy in primitive psychogenic premature ejaculation resistant to psychotherapy. Eur Urol 1995; 28: 126-30.

65 Basar MM, Yilmaz E, Ferhat M, Basar H, Batislam E. Terazosin in the treatment of premature ejaculation: a short-term follow-up. Int Urol Nephrol 2005; 37: 773-7.

66 Xin ZC, Chung WS, Choi YD, Seong DH, Choi YJ et al. Penile sensitivity in patients with primary premature ejaculation. J Urol 1996; 156: 979-81.

67 Xin ZC, Choi YD, Rha KH, Choi HK. Somatosensory evoked potentials in patients with primary premature ejaculation. J Urol 1997; 158: 451-5.

68 Xin ZC, Choi YD, Seong DH, Choi HK. Sensory evoked potential and the effect of SScream in premature ejaculation. Yonsei Med J 1995; 36: 397-401.

69 Xin ZC, Choi YD, Lee WH, Chun DC, Choi HK et al. Changes in ejaculatory latency and penile vibratory threshold with SS-cream in patients with primary premature ejaculation. Sex Dysfunct 1998; 1: 89-93.

70 Xin ZC, Choi YD, Lee SH, Choi HK. Efficacy of a topical agent SS-cream in the treatment of premature ejaculation: preliminary clinical studies. Yonsei Med J 1997; 38: 91-5.

71 Choi HK, Jung GW, Moon KH, Moon KH, Xin ZC et al. Clinical study of SS-cream in patients with lifelong premature ejaculation. Urology 2000; 55: 257-61.

72 Tian L, Xin ZC, Xin H, Fu J, Yuan YM et al. Effect of renewed SS-cream on spinal somatosensory evoked potentials in rabbits. Asian J Androl 2004; 6: 15-8.

73 Busato W, Galindo CC. Topical anaesthetic use for treating premature ejaculation: a double-blind, randomized, placebo-controlled study. BJU Int 2004; 93: 1018-21.

74 Atikeler MK, Gecit I, Senol FA. Optimum usage of prilocaine-lidocaine cream in premature ejaculation. Andrologia 2002; 34: 356-9.

75 Morales A, Barada J, Wyllie MG. A review of the current status of topical treatments for premature ejaculation. BJU Int 2007; 100: 493-501.

76 Giuliano F. Interview with Dr Francois Giuliano (by Christine McKillop). New avenues in the pharmacological treatment of premature ejaculation. Eur Urol 2007; 52: 1254-7.

77 Waldinger MD. Relevance of an evidence-based ejaculation time cutoff point for neurobiological research of premature ejaculation. J Comp Neurol 2005; 493: 4650 . 
78 Gengo PJ, Giuliano F, McKenna KE, Chester A, Lovenberg T et al. Monoaminergic transporter binding and inhibition profile of dapoxetine, a medication for the treatment of premature ejaculation. J Urol 2005; 173 (Suppl 4): 239-44.

79 Andersson KE, Mulhall JP, Wyllie MG. Pharmacokinetic and pharmacodynamic features of dapoxetine, a novel drug for 'on-demand' treatment of premature ejaculation. BJU Int 2006; 97: 311-5

80 Pryor JL, Althof SE, Steidle C, Rosen RC, Hellstrom WJ et al. Efficacy and tolerability of dapoxetine in the treatment of premature ejaculation: integrated analysis of two randomized, double-blind, placebo-controlled trials. Lancet 2006; 368: 929-37.

81 Buvat J, Tesfaye F, Rothman M, Rivas DA, Giuliano F. Dapoxetine for the treatment of premature ejaculation: results from a randomized, double-blind, placebo-controlled phase 3 trial in 22 countries. Eur Urol 2009; 55: 957-68.

82 Shabsigh R, Broderick G, Miloslavsky M, Bull S, Nilsson-Neijber A. Long-term safety and tolerability of dapoxetine for the treatment of men with premature ejaculation. Proceedings of the 21st Annual Congress of the European Association of Urology; 5-8 April 2006; Paris, France. European Association of Urology: Arnhem, The Netherlands, 2006

83 Taber MT, Wright RN, Molski TF, Clarke WJ, Brassil PJ et al. Neurochemical, pharmacokinetic, and behavioral effects of the novel selective serotonin reuptake inhibitor BMS-505130. Pharmacol Biochem Behav 2005; 80: 521-8.

84 Azam U. Late-stage clinical development in lower urogenital targets: sexual dysfunction. Br J Pharmacol 2006; 147 (2 Suppl): S153-9.

85 Henry R, Morales A. Topical lidocaineprilocaine spray for the treatment of premature ejaculation: a proof of concept study. Int J Impot Res 2003; 15: 277-81.

86 Dinsmore WW, Hackett G, Goldmeier D, Waldinger M, Dean J et al. Topical eutectic mixture for premature ejaculation (TEMPE): a novel aerosol-delivery form of lidocaineprilocaine for treating premature ejaculation. BJU Int 2007; 99: 369-75.
87 Padma-Nathan $\mathrm{H}$, Yeager JL. An integrated analysis of al prostadil topical cream for the treatment of erectile dysfunction in 1732 patients. Urology 2006; 68: 386-91.

88 Cremers T, de Boer P, Liao Y, Bosker FJ, den Boer JA et al. Augmentation with a 5 HT1A, but not a 5-HT1B receptor antagonist critically depends on the dose of citalopram. Eur J Pharmacol 2000; 397: 63-74.

89 Williamson IJ, Turner L, Woods K, Wayman CP, van der Graaf PH. The 5-HT1A receptor antagonist robalzotan enhances SSRI-induced ejaculation delay in the rat. Br J Pharmacol 2003; 138 (Suppl 1): P032.

90 de Jong TR, Pattij T, Veening JG, Dederen PJ, Waldinger MD et al. Citalopram combined with WAY 100635 inhibits ejaculation and ejaculationrelated Fos immunoreactivity. Eur J Pharmacol 2005; 509: 49-59.

91 Filippi S, Morelli A, Vignozzi L, Vannelli GB, Marini M et al. Oxytocin mediates the estrogen-dependent contractile activity of endothelin-1 in human and rabbit epididymis. Endocrinology 2005; 146: 3506-17.

92 Shi WG, Wang XJ, Liang XQ, Liu ZQ, Huang MJ et al. Selective resection of the branches of the two dorsal penile nerves for primary premature ejaculation. Zhonghua Nan Ke Xue 2008; 14: 436-8.

93 Waldinger MD, Olivier B. Animal models of premature and retarded ejaculation. World J Urol 2005; 23: 115-8.

94 Olivier B, Chan JS, Pattij T, de Jong TR, Oosting RS et al. Psychopharmacology of male rat sexual behavior: modeling human sexual dysfunctions? Int J Impot Res 2006; 18 (Suppl 1): S14-23.

95 Pattij T, de Jong T, Uitterdijk A, Waldinger MD, Veening JG et al. Individual differences in male rat ejaculatory behavior: searching for models to study ejaculation disorders. Eur J Neurosci 2005; 22: 724-34.

96 Pattij T, Olivier B, Waldinger MD. Animal models of ejaculatory behavior. Curr Pharm Des 2005; 11: 4069-77. 